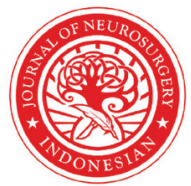

\section{Occipital dural fistula presenting with hydrocephalus: A case report}

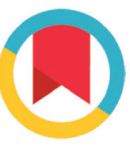

CrossMark
Indonesian Journal of Neurosurgery

'Department of Neurosurgery, All India Institute of Medical Sciences, Saket

Nagar, Bhopal, Madhya Pradesh, India;

${ }^{2}$ Facultad de Ciencias de la Salud, Universidad del Sinu Elias Bechara Zainum, Cartagena de Indias, Colombia; ${ }^{3}$ Medical Research. Latinoamerican Council of Neurointensivism, Cartagena, Colombia;

${ }^{4}$ Neurosurgeon-Critical Care. Center for Biomedical Research (CIB). Director of Research Line Cartagena Neurotrauma Research Group. Faculty of Medicine University of Cartagena. Cartagena de Indias, Colombia;

*Corresponding author:

Ammit Agrawal;

Department of Neurosurgery, All India Institute of Medical Sciences, Saket Nagar, Bhopal, Madhya Pradesh, India; dramitagrawal@gmail.com

Received: 2021-05-24

Accepted: 2021-10-22

Published: 2021-12-03

\author{
Ammit Agrawal ${ }^{2 *}$, Harold Vasquez ${ }^{2,3}$, William A Florez ${ }^{3}$, \\ Luis Rafael Moscote-Salazar ${ }^{4}$
}

\section{ABSTRACT}

Introduction: Dural arteriovenous fistula (DAVF) is an abnormal vascular communication between branches of dural arteries and dural veins or venous sinuses. These fistulas are associated with hydrocephalus in $35 \%$ of cases in the pediatric population. However, the presence of hydrocephalus in adults is rare in DAVF. We presented a case report of DAFV accompany by hydrocephalus and was managed with endovascular therapy.

Case presentation: A 15-year-old school girl presented with nausea and vomiting for two weeks. She had spastic paraparesis and cognitive impairment. Her mother had a history of cerebral arteriovenous malformation that was associated with hydrocephalus. Magnetic resonance imaging was further examined and revealed dilation of both lateral ventricular and hyperintensity on the periventricular area. Diagnostic angiography was performed which showed the presence of a dural fistula between occipital sinus and multi-side of Galen vein. Embolization with onyx was performed successfully.

Conclusion: DAVF in our case was a rare condition with an atypical localization. Further study will be needed to describe this rare entity and to establish its true prevalence.

Keywords: dural arteriovenous fistula, endovascular therapy, hydrocephalus, occipital.

Cite This Article: Agrawal, A., Vasquez, H., Florez, W.A., Salazar, L.R.M. 2021. Occipital dural fistula presenting with hydrocephalus: A case report. Indonesian Journal of Neurosurgery 4(3): 91-93. D0I: 10.15562/ijn.v4i3.134

\section{INTRODUCTION}

Dural arteriovenous fistula (DAVF) is an acquired vascular lesion with direct dural arterial and cerebral venous sinuses or cortical veins communication. ${ }^{1}$ Historically, it was considered a congenital lesion and usually presented in the second or third decades of life. The clinical manifestation is usually intracranial hemorrhage and classified as intraparenchymal, intraventricular, and subarachnoid based on its location. Other clinical manifestations are seizures, nonspecific headaches, and focal neurological deficit. However, the clinical presentation with features of increased intracranial pressure and radiological presence of hydrocephalus is extremely unusual in adults. Hydrocephalus may constitute a presenting symptom in up to $35 \%$ of cases in the pediatric population. ${ }^{2}$

Although DAVF may present anywhere within the dura mater, it mostly occurs in relation to the sigmoid, transverse, or cavernous sinuses. ${ }^{1,3}$ The exact etiology of this condition is still not well understood. However, it is hypothesized that it is occurred due to enlargement of the previous presence of physiologic shunts and increased local venous pressure due to sinus thrombosis. Other hypothesis includes neo-angiogenesis due to venous sinus outflow obstruction, venous hypertension, and decreased cerebral perfusion. ${ }^{3}$ In this article, we presented a case report of DAFV accompany by hydrocephalus and was managed with endovascular therapy.

\section{CASE PRESENTATION}

A 15-year-old school girl presented with nausea and vomiting for two weeks. She had a history of cardiac arrest which required cardiopulmonary resuscitation at 20 days old secondary to fulminant pneumonia. She also developed cognitive impairment since then. In family history, her mother had a history of hydrocephalus and cerebral arteriovenous malformation.

On initial computed tomography scan, it showed the presence of obstructive hydrocephalus and the presence of dural arteriovenous fistula (Fig. 1A). Magnetic resonance imaging was further examined and revealed dilation of both lateral ventricular and hyperintensity on the periventricular area (Fig. 1B).

Diagnostic angiography was performed which showed the presence of a dural fistula between occipital sinus and multiside of Galen vein (Fig. 2).

Embolization with onyx was performed successfully. The patient recovered with favorable improvement and was discharged seven days following endovascular therapy.

\section{DISCUSSION}

Obstruction of the cerebrospinal fluid pathway in the ventricles system by an enlargement drainage vein or brain arteriovenous malformations had been also implicated as the cause of hydrocephalus. However, distant venous outflow obstruction that produces 


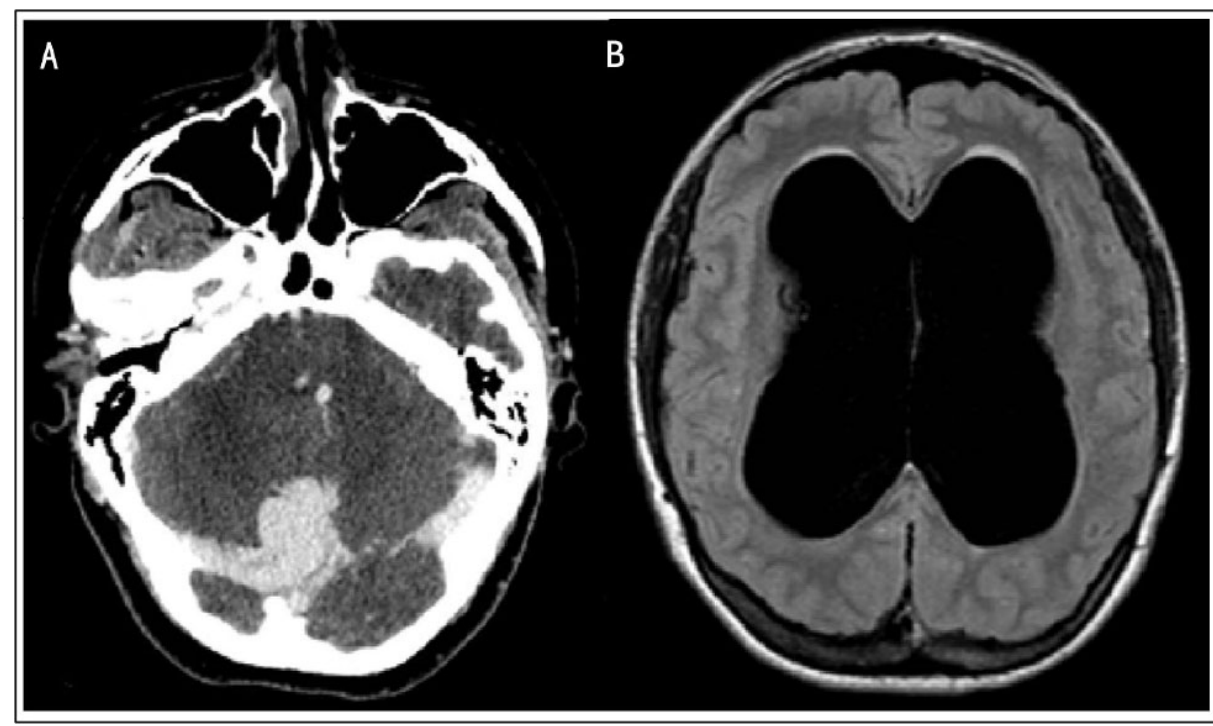

Figure 1. A. Head computed tomography scan with contrast administration showing the presence of a dural arteriovenous fistula. B. Initial brain magnetic resonance imaging, axial section, T1W image showing gross ventricular dilation with thinning of cortex with hyperintensity in periventricular area.

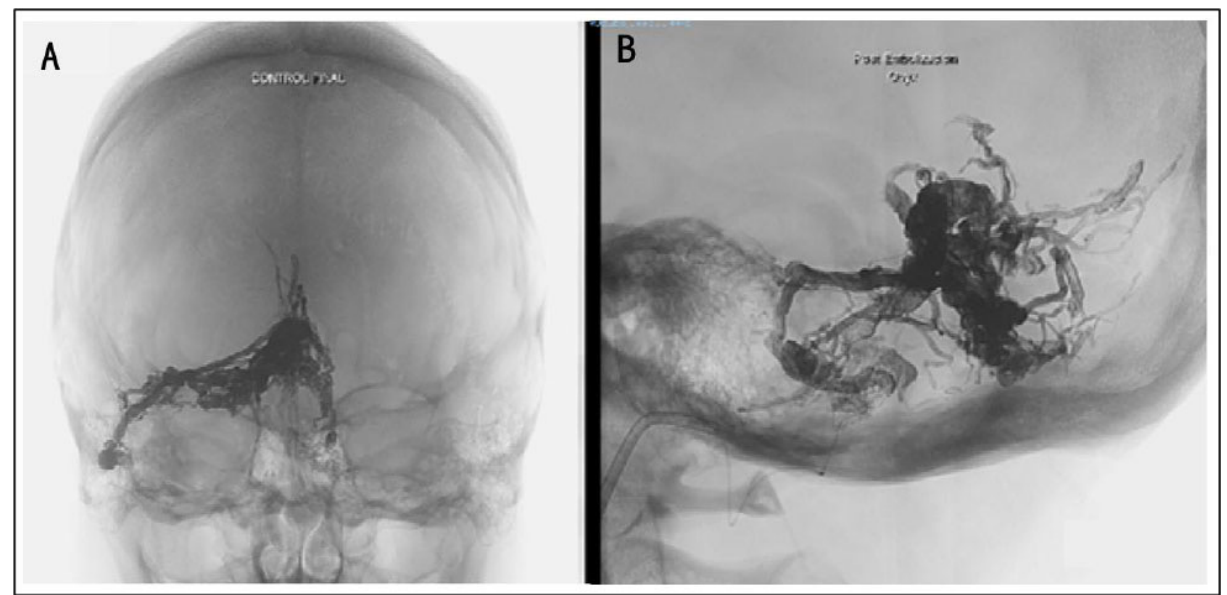

Figure 2. A. Anteroposterior (AP) view of angiogram showing the presence of dural arteriovenous fistula and its relationship with occipital sinus and vein of Galen. B. Lateral view of digital subtraction angiogram showing the presence of dural arteriovenous fistula and its relationship with occipital sinus and vein of Galen.

venous congestion had not been described yet for the adult population., ${ }^{2,4}$ Hydrocephalus is rarely associated with DAVF. There was a study reporting hydrocephalus associated with spinal perimedullary $\mathrm{AVM}^{3}{ }^{3}$ In arteriovenous malformation, hydrocephalus can be occurred due to rupture of DAVF and leads to intraventricular or subarachnoid hemorrhage. This hemorrhage can lead to subsequent blockage of the arachnoid villi or intracranial cisterns surrounding hydrocephalus was due to a combination of poor venous drainage and mass effect from dilated sinuses. ${ }^{3}$

Nakahara et al. reported a case of normal pressure hydrocephalus which was associated with cortical venous reflux from transverse-sigmoid to superior sagittal sinus. It also may have impaired venous drainage due to venous hypertension from the fistula. In that case, hydrocephalus was caused by a difference in pressure between the venous sinuses and subarachnoid space. ${ }^{2,3}$

Cerebrospinal fluid is absorbed from the subarachnoid compartment through arachnoid villi or granulations that project into the venous sinuses of the dura mater on the cerebral convexity. ${ }^{2,6}$ Hydrocephalus secondary due to venous hypertension may be observed in younger patients with high flow fistulae and vein of Galen malformations without ventricular obstruction.

In DAVF, intraventricular hemorrhage may also cause obstructive hydrocephalus. Kataoka et al. reported a case of obstructive hydrocephalus resulting from small hemorrhage in lateral and third ventricles and shown spontaneous resolution. ${ }^{7}$ Satoh et al. reported four cases of cerebellar hemorrhage near the fourth ventricle and all of them developed hydrocephalus. ${ }^{8}$ In our case, hydrocephalus might have been caused by progressive parenchymal venous engorgement due to high-pressure venous reflux. This is a novel mechanism that neurosurgeons should be well aware of.

The clinical manifestation of DAVF is usually related to the flow through the fistula which causes pulsatile tinnitus or cavernous sinus symptoms in the case of carotid-cavernous fistula. Besides frank hemorrhage, the varieties of nonhemorrhagic neurologic deficits reported were myriad due to the heterogeneous nature of the lesions. ${ }^{2,3}$

Although raised intracranial pressure is common in DAVF due to increased venous pressure, hydrocephalus is an uncommon presentation except in the case of tentorial DAVF. Hydrocephalus in DAVF may be observed in up to $28 \%$ of total cases. Presumably, it was related to compression of the cerebral aqueduct caused by venous enlargement. ${ }^{9,10}$ 
In infants with open fontanelle, hydrocephalus leads to an increase in head circumference due to its ability to expand the intracranial compartment. However, in older children and adults, hydrocephalus leads to raised intracranial pressure due to rigid and fixed intracranial compartments. Earlier, DAVF required surgical disconnection of the fistula to the affected sinus. However, with the advancement of modern endovascular therapy techniques, high-risk fistula can be managed with embolization of Onyx (Ethylene-vinyl alcohol; Covidien neurovascular, Dublin, Ireland), either transarterial, venous outflow occlusion or combination with surgical treatment. In our current case, the hydrocephalus was caused by venous congestion of the vein of Galen due to the presence of DAVF.

Wilson et al. reported a case of communicating hydrocephalus which was caused by an unruptured arteriovenous fistula located in the perimedullary region at L1 level. They postulated that either central venous hypertension or reduced cerebrospinal fluid resorption was the cause of hydrocephalus. Central venous hypertension was thought to be caused by a high-flow fistula. Reduced cerebrospinal fluid resorption through arachnoid granulation in the lumbar region of the spinal cord was thought to be caused by the change in cerebrospinal fluid hydrodynamic.

Regarding the management, initial treatment should focus on the management of the fistula. Hydrocephalus should be managed only when necessary. ${ }^{1,3,11,12}$

\section{CONCLUSION}

The prevalence of the DAVF of the occipital sinus accompany by hydrocephalus due to vein of Galen congestion is not clear. Venous dilatation due to DAVF is the cause of hydrocephalus due to obstruction of cerebrospinal circulation. More studies are needed to investigate this pathology to determine its prevalence and pathophysiological mechanism.

\section{FUNDING}

All authors stated that there are no financial or other potential conflicts of interest.

\section{CONFLICT OF INTEREST}

None.

\section{AUTHOR CONTRIBUTION}

All authors contributed to data collection, literature review, design, writing, and revision of the manuscript.

\section{REFERENCES}

1. Gandhi D, Chen J, Pearl M, Huang J, Gemmete JJ, Kathuria S. Intracranial dural arteriovenous fistulas: classification, imaging findings, and treatment. AJNR Am J Neuroradiol. 2012; 33(6): 1007 - 13. https://doi.org/10.3174/ajnr.A2798.

2. Geibprasert S, Pereira V, Krings T, Jiarakongmun P, Lasjaunias P, Pongpech S. Hydrocephalus in unruptured brain arteriovenous malformations: Pathomechanical considerations, therapeutic implications, and clinical course. J Neurosurg. 2009; 110(3): 500 507. https://doi.org/10.3171/2008.7.JNS0815.

3. Ernst GL, Carlson AP. Transverse sinus dural arteriovenous fistula presenting with zcute hydrocephalus from cerebellar venous engorgement resolving with endovascular treatment. J Neurol Surg A Cent Eur Neurosurg. 2016; 77(6): 538 - 42. https://doi. org $/ 10.1055 / \mathrm{s}-0035-1563558$.

4. Pribil S, Boone SC, Waley R. Obstructive hydrocephalus at the anterior third ventricle caused by dilated veins from an arteriovenous malformation. Surg Neurol. 1983; 20(6):
487 - 492. https://doi.org/10.1016/00903019(83)90032-0.

5. Toma AK. Hydrocephalus. Surgery. 2015; 33(8): $384-9$.

6. Nakahara Y, Ogata A, Takase Y, Maeda K, Okamoto H, Matsushima T, Sakata S. Treatment of dural arteriovenous fistula presenting as typical symptoms of hydrocephalus caused by venous congestion: case report. Neurol Med Chir. 2011; 51(3): 229 - 32. https://doi. org/10.2176/nmc.51.229.

7. Kataoka K, Taneda M. Angiographic disappearance of multiple dural arteriovenous malformations. Case report. J Neurosurg. 1984; 60(6): 1275 - 1278. https://doi.org/10.3171/ ins.1984.60.6.1275.

8. Satoh K, Satomi J, Nakajima N, Matsubara S, Nagahiro S. Cerebellar hemorrhage caused by dural arteriovenous fistula: A review of five cases. J Neurosurg. 2001; 94(3): 422 - 426. https://doi.org/10.3171/jns.2001.94.3.0422.

9. Lasjaunias $\mathrm{P}$, Chiu $\mathrm{M}$, ter Brugge $\mathrm{K}$, Tolia A, Hurth M, Bernstein M. Neurological manifestations of intracranial dural arteriovenous malformations. J Neurosurg. 1986; 64(5): 724 - 30. https://doi.org/10.3171/ jns.1986.64.5.0724.

10. Lewis AI, Tomsick TA, Tew Jr JM. Management of tentorial dural arteriovenous malformations: Transarterial embolization combined with stereotactic radiation or surgery. J Neurosurg. 1994; 81(6): 851 - 9. https://doi.org/10.3171/ jns.1994.81.6.0851.

11. Carlson AP, Taylor CL, Yonas H. Treatment of dural arteriovenous fistula using ethylene vinyl alcohol (onyx) arterial embolization as the primary modality: short-term results. $J$ Neurosurg. 2007; 107(6): 1120 - 5. https://doi. org/10.3171/JNS-07/12/1120.

12. Wilson MP, Aronyk KE, Yeo T, Chow M, Pugh JA. Communicating hydrocephalus caused by an unruptured perimedullary arteriovenous fistula in the lumbar region of an infant. $J$ Neurosurg Pediatr. 2013; 11(3): 346 - 9. https:// doi.org/10.3171/2012.11.PEDS12244.

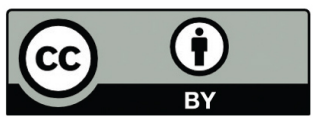

This work is licensed under a Creative Commons Attribution 